\title{
Power Systems Resilience Assessment: Hardening and Smart Operational Enhancement Strategies
}

DOI:

10.1109/JPROC.2017.2691357

\section{Document Version}

Accepted author manuscript

Link to publication record in Manchester Research Explorer

\section{Citation for published version (APA):}

Panteli, M., Trakas, D. N., Mancarella, P., \& Hatziargyriou, N. D. (2017). Power Systems Resilience Assessment: Hardening and Smart Operational Enhancement Strategies. Institute of Electrical and Electronics Engineers. Proceedings , 105(7), 1202 - 1213. https://doi.org/10.1109/JPROC.2017.2691357

\section{Published in:}

Institute of Electrical and Electronics Engineers. Proceedings

\section{Citing this paper}

Please note that where the full-text provided on Manchester Research Explorer is the Author Accepted Manuscript or Proof version this may differ from the final Published version. If citing, it is advised that you check and use the publisher's definitive version.

\section{General rights}

Copyright and moral rights for the publications made accessible in the Research Explorer are retained by the authors and/or other copyright owners and it is a condition of accessing publications that users recognise and abide by the legal requirements associated with these rights.

\section{Takedown policy}

If you believe that this document breaches copyright please refer to the University of Manchester's Takedown Procedures [http://man.ac.uk/04Y6Bo] or contact uml.scholarlycommunications@manchester.ac.uk providing relevant details, so we can investigate your claim.

\section{OPEN ACCESS}




\title{
Power Systems Resilience Assessment: Hardening and Smart Operational Enhancement Strategies
}

\author{
Mathaios Panteli, Member, IEEE, Dimitris N. Trakas, Student Member, IEEE, Pierluigi Mancarella, \\ Senior Member, IEEE, and Nikos D. Hatziargyriou, Fellow, IEEE
}

\begin{abstract}
Power systems have typically been designed to be reliable to expected, low-impact high-frequency outages. In contrast, extreme events, driven for instance by extreme weather and natural disasters, happen with low-probability, but can have a high impact. The need for power systems, possibly the most critical infrastructures in the world, to become resilient to such events is becoming compelling. However, there is still little clarity as to this relatively new concept. On these premises, this paper provides an introduction to the fundamental concepts of power systems resilience and to the use of hardening and smart operational strategies to improve it. More specifically, first the resilience trapezoid is introduced as visual tool to reflect the behavior of a power system during a catastrophic event. Building on this, the key resilience features that a power system should boast are then defined, along with a discussion on different possible hardening and smart, operational resilience enhancement strategies. Further, the so-called $\Phi$ АEП resilience assessment framework is presented, which includes a set of resilience metrics capable of modelling and quantifying the resilience performance of a power system subject to catastrophic events. A case study application with a 29-bus test version of the Great Britain transmission network is carried out to investigate the impacts of extreme windstorms. The effects of different hardening and smart resilience enhancement strategies are also explored, thus demonstrating the practicality of the different concepts presented.
\end{abstract}

Index Terms-Extreme Weather, Natural Disasters, Resilience, Resiliency, Critical infrastructure, Smart Grids

\section{INTRODUCTION}

$\mathrm{E}$ LECTRICAL power systems are the backbone of any modern society, supporting several other critical infrastructures, such as transportation, communication, water, etc. [1]. A disruption in the continuous electricity supply will thus have catastrophic consequences, as experienced during numerous blackouts in the last decades [2, 3].

However, ensuring an uninterrupted electricity supply is challenging, as power systems are exposed to several threats.

M. Panteli is with the The University of Manchester, M13 9PL, UK (email: mathaios.panteli@manchester.ac.uk).

D. N. Trakas and N. D. Hatziargyriou are with the National Technical University of Athens, Athens 157 73, Greece (e-mail: dtrakas@power.ece.ntua.gr; nh@power.ece.ntua.gr).

P. Mancarella is with The University of Melbourne, Victoria 3010, Australia, and with The University of Manchester, M13 9PL, UK (emails pierluigi.mancarella@unimelb.edu.au; p.mancarella@manchester.ac.uk).
TABLE I

COMPARISON OF TYPICAL POWER SYSTEM OUTAGES AND NATURAL DISASTERS/EXTREME WEATHER

\begin{tabular}{ll}
\hline \hline Typical Power System Outage & Natural Disaster/Extreme Weather \\
\hline - Low impact, high probability & - High impact, low probability \\
- More predictable/controllable & - Less predictable/controllable \\
- Random location and time of & - Spatiotemporal correlation \\
occurrence & between faults and event \\
- Supported by contingency & - Unforeseen event \\
analysis tools & \\
- Limited number of faults due & - Multiple faults \\
to component failures & - Large portion of the network is \\
- Network remains intact & damaged/collapsed \\
- Quick restoration & $\begin{array}{l}\text { More time and resources } \\
\text { consuming/longer restoration }\end{array}$ \\
\hline \hline
\end{tabular}

These threats can be mainly categorized in typical power system outages and extreme events, driven for instance by natural disasters/extreme weather. There are distinct differences between these two categories, as shown in Table I [4]. Hence, electrical power systems have been designed in a way that they possess high levels of reliability to the more typical threats. Latest events are now creating compelling cases for power systems to also boast high levels of resilience to natural disasters and extreme weather, to reduce the frequency and severity of power disruptions.

Power systems reliability is a well-known and established concept, and several reliability-oriented studies have been developed by power system engineers and scholars. In contrast, there is much less clarity as to the concept of resilience. "Resilience" originates from the Latin word "resilio" and, having been first introduced by C.S. Holling in 1973 for ecological systems [5], is a relatively new and emerging concept in the area of power systems. Within this context, power systems resilience can be referred to as the ability of a power system to recover quickly following a disaster or, more generally, to the ability of anticipating extraordinary and high-impact, low-probability events, rapidly recovering from these disruptive events, and absorbing lessons for adapting its operation and structure to be better prepared for similar events in the future [6, 7]. A framework for power systems resilience, along with its key differences with power systems reliability, are presented in [8,9]. If the impacts of 


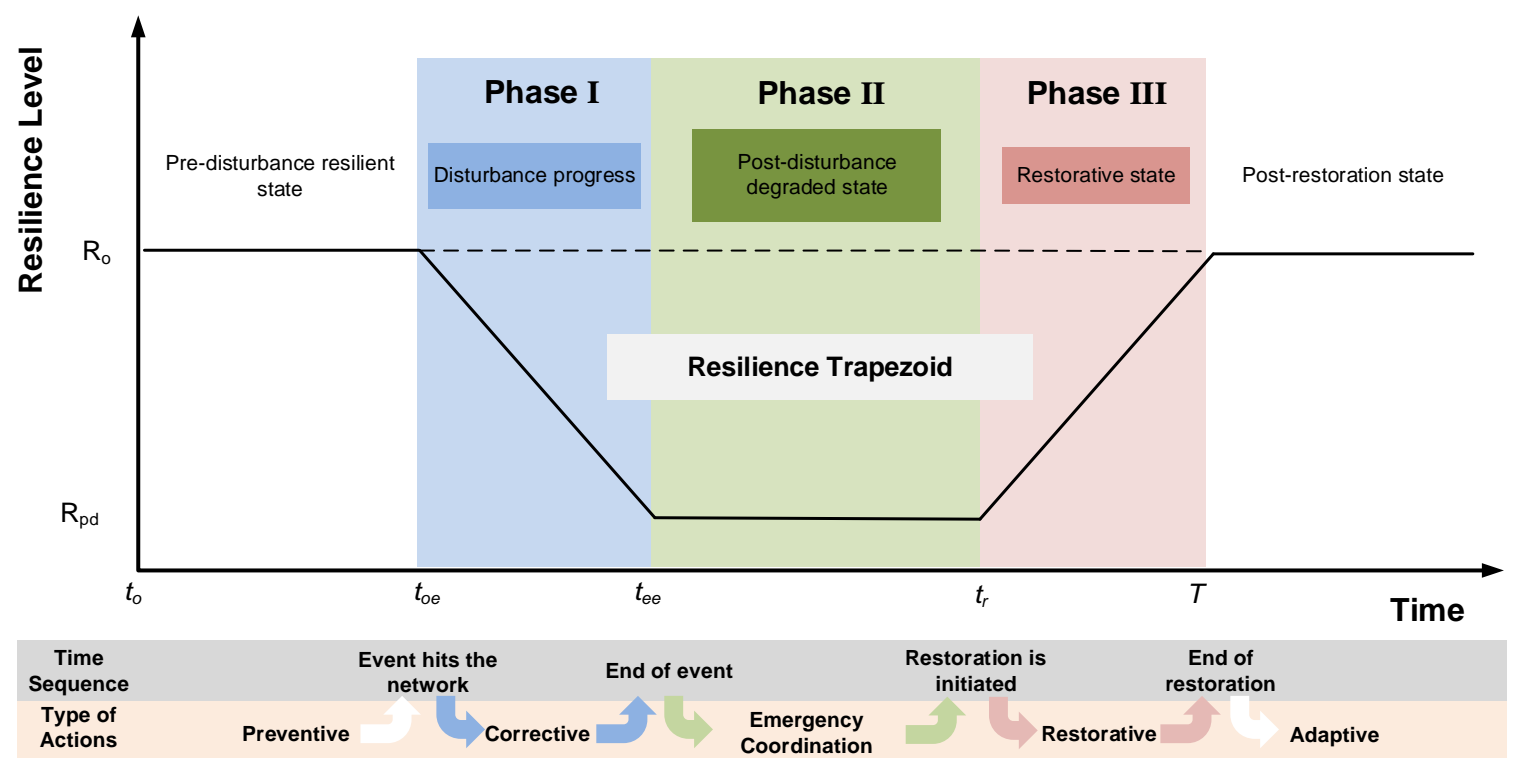

Fig. 1. Conceptual resilience trapezoid associated to an event

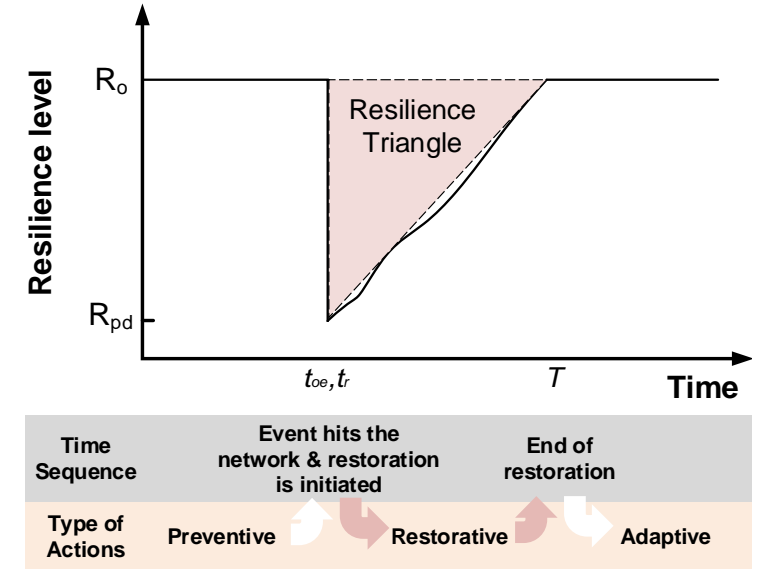

Fig. 2. The resilience triangle associated to an event [10]

TABLE II

RESILIENCE TRIANGLE Vs RESILIENCE TRAPEZOID

\begin{tabular}{ll}
\hline \hline \multicolumn{1}{c}{ Resilience Triangle } & \multicolumn{1}{c}{ Resilience Trapezoid } \\
\hline - Single-phase resilience & $\bullet$ Dynamic, multi-phase resilience \\
assessment & assessment \\
- Lack of corrective actions & - Considers corrective actions \\
during the progress of an event & \\
- Lack of post-disturbance & - Considers post-disturbance \\
degraded state & degraded state and its duration \\
- Threat-specific & Applicable to any threat \\
\hline \hline
\end{tabular}

climate change and the need to go greener with reduced GHG emissions are also considered, then this leads to the so-called "low-carbon resilient" future networks, including both carbon reduction and resilience goals $[11,12]$.

The aim of this article is to introduce and discuss the fundamental concepts of power systems resilience and its key features. Such an understanding would enable the development of quantitative resilience assessment methods and the evaluation of the contribution of different strategies (hardening and smart operational) for enhancing resilience to natural disasters and extreme weather.

\section{Defining, QuANTIFying AND Boosting Power Systems RESILIENCE}

In this section, a conceptual resilience trapezoid is first discussed for defining and understanding resilience, followed by a discussion on quantitative resilience metrics and resilience enhancement strategies (including hardening and smart operational measures).

\section{A. The conceptual resilience trapezoid}

A power system might reside in different states when imposed to an external shock, such as natural disaster or extreme weather. It is therefore critically important to define these states, in order to enable the systematic resilience assessment and enhancement of power systems to such events.

Under these premises, Fig. 1 shows a conceptual resilience trapezoid, which clearly demonstrates the states (phases) of a power system associated to an external disturbance, as well the time sequence of these states and related events and the type of available actions. Breaking the event into different phases (namely Phases I, II and III) enables the dynamic, multi-phase resilience assessment. This is a significant advantage of the resilience trapezoid when compared with the so-called resilience triangle (Fig. 2) traditionally used and modelled in past resilience studies [13-15]. The resilience triangle is only capable of conducting single-phase resilience assessment, and in particular of assessing the recovery performance of an infrastructure following the event, as can be seen in Fig. 2. An additional advantage of the resilience trapezoid is that it is applicable to any threat, irrespective of its nature. Moreover, the assumption of a sharp and immediate resilience degradation in the resilience triangle approach deems this approach threat-specific, for example when it is hit by an earthquake whose duration is secs mins and a sharp resilience decrease occurs. The resilience triangle is not able to capture the evolution of an event, such as a typhoon, which could last from hours to days. Further differences between the two approaches are shown in Table II. 
The various phases of the power system state can be accurately represented by the resilience trapezoid model, as follows: If the time and location of the external shock can be sufficiently predicted, the system operator should proceed to the application of preventive actions (e.g. preventive generation re-scheduling) before the event hits the network at $t_{o e}$. The aim of these actions is the boosting of the predisturbance resilience of the infrastructure. During the disturbance progress (Phase $I, t \in\left[t_{o e}, t_{e e}\right]$ ), emergency or corrective actions (e.g. generation re-dispatch) can mitigate the impact of external shock on power system. Following the event, the system will reside in the post-disturbance degraded state (Phase II, $t \in\left[t_{e e}, t_{r}\right]$ ), where proper and effective emergency coordination and preparedness would enable the quick commencing of the restoration phase (Phase III, $t \in\left[t_{r}\right.$, $T$ ], where $T$ is the time that the network fully recovers from its post-disturbance resilience level $R_{p d}$ to its pre-disturbance resilience level $R_{0}$ as shown in Fig. 1, or to a desired resilience level which can be different than $R_{0}$ ) and the application of the restorative actions. When the system recovers from the postevent degraded state, the impacts of the external shock on system resilience and its performance during the event need to be assessed and analyzed, so that adaptive actions can be taken in order to increase the resilience of the infrastructure during future similar or unforeseen events.

The resilience trapezoid of Fig. 1 is based on the assumption that the entire infrastructure is exposed to the event during Phase $I$ and that no restoration of the damaged components is performed during the event. The latter is the usual practice followed in case of disastrous external shocks, like severe windstorms, for safety reasons. If it is considered that the restoration of one affected part of the infrastructure is initiated while another part of the infrastructure is still exposed to the event, then a non-flat bottom of the trapezoid might be observed and multiple times would have to be defined, e.g. multiple $t_{e e}$ and $t_{r}$ corresponding to the times that each part of the infrastructure is no longer subject to the event and to the time the restoration is initiated respectively. This would be needed to distinguish the phases of the resilience trapezoid.

\section{B. Key resilience features}

Within the broad definition of power systems resilience given in Section I and the resilience trapezoid curve of Fig.1, a resilient power system should possess the following key resilience features:

- Pre-disturbance resilient state: A sufficient estimation of the event's location and severity would enable the application of preventive actions and the network configuration in a state that would help the system operator to deal effectively with the upcoming event. It would also enable the prepositioning of the resources possibly required following the event, e.g. repair and recovery crews, mobile generators, etc. Therefore, preventive operational flexibility is critically important.

- Phase I, Disturbance Progress: High robustness/ resistance and redundancy would help boost the resilience to the initial impacts of the external shock and reduce the level of resilience degradation (i.e., $R_{o}-R_{p d}$, see Fig. 1). Further, resourcefulness (supported by smart grid technologies, e.g. advanced monitoring and distributed energy systems) is particularly important as it provides the corrective operational flexibility required for dealing with the prevailing conditions and reducing the slope/speed of the resilience degradation. Also, advanced information systems would help develop high situation awareness allowing the system operators to remain adequately informed on the evolving conditions.

- Phase II, Post-disturbance Degraded State: Disaster assessment and priority setting and proper emergency preparedness and coordination would help the system operator to assess the damage by the event, identify the critical components for the recovery of the system to a resilient state and initiate as fast as possible the procedures for restoring the damaged infrastructure. This reduces the duration of Phase II, i.e., $t_{e e}-t_{r}$ (see Fig. 1).

- Phase III, Restorative State: Following the actions in Phase II, a resilient system should demonstrate high restorative capabilities in order to first restore the disconnected customers (i.e., operational resilience) and then restore the collapsed infrastructure (i.e., infrastructure resilience). Several actions should take place in this phase, such as reenergizing transmission and distribution lines, restoration of damaged components, unit restarting, resynchronization of areas, load restoration, etc. The aim of these actions should be to reduce the duration of Phase III, i.e., $T$ - $t_{r}$ (see Fig. 1).

- Post-restoration state: Following the event and the restoration of the infrastructure to a resilient state, the impact of the event and the performance of the network should be thoroughly analyzed to identify weaknesses or limitations of the network, which could be improved to be better prepared for future (similar or unforeseen) events. Therefore, being adaptive and reflective to the experiences gained through the different events and threats is a key feature of a resilient infrastructure.

If a power system possesses the key resilience features mentioned throughout the different phases of an event, then it should be capable of effectively anticipating the impacts of the upcoming event, rapidly recover from the degraded to a resilient state and adapt its operation and structure to reduce the effects of future events.

\section{Quantitative resilience metrics}

Several studies have been developed in order to quantitatively assess power systems resilience to natural hazards and extreme weather [13-24].

The quantitative resilience metrics should ideally be timedependent, in order to capture the performance of the network during the different phases associated with an event. Within this context, the $\Phi \Lambda E \Pi$ resilience metric system [25] shown in Table III is proposed for quantifying the resilience trapezoid of Fig. 1. In particular, these metrics refer to the how fast $(\Phi)$ and how low $(\Lambda)$ resilience drops in Phase I, how extensive (E) is the post-event degraded state (Phase II) and how promptly (II) the network recovers to its pre-event resilient state (Phase III). It should be noted here that a post-event resilience level 
TABLE III

THE ФИЕП RESILIENCE METRIC SYSTEM

\begin{tabular}{c|c|c|c}
\hline Phase & State & Resilience metric & Symbol \\
\hline I & $\begin{array}{c}\text { Disturbance } \\
\text { progress }\end{array}$ & $\begin{array}{c}\text { How fast resilience drops? } \\
\text { How low resilience drops? }\end{array}$ & $\Phi$ \\
\hline II & $\begin{array}{c}\text { Post-disturbance } \\
\text { degraded }\end{array}$ & $\begin{array}{c}\text { How extensive is the post- } \\
\text { disturbance degraded state? }\end{array}$ & $E$ \\
\hline III & Restorative & $\begin{array}{c}\text { How promptly does the network } \\
\text { recover? }\end{array}$ & $\Pi$ \\
\hline
\end{tabular}

could also be defined, which might differ from the pre-event level. For simplicity, here we do not explicitly deal with this aspect, which can be system- and event-specific. However, the proposed framework possesses the capability to address it.

These metrics can be easily quantified using the different resilience levels and discrete times of the resilience trapezoid. The $\Phi$-metric in Phase I is given by the slope of the resilience degradation $R_{o}-R_{p d}$ during the event $\left(t \in\left[t_{o e}, t_{e e}\right]\right.$ ), while the $\Lambda$ metric is defined by the resilience degradation level at the end of the event at $t_{e e}$, i.e., $R_{o}-R_{p d}$. The E-metric, showing the time that the network remains in the post-disturbance degraded state (Phase II), is given by $t_{r}-t_{e e}$. The $\Pi$-metric in Phase III is defined by the slope of the resilience recovery curve, which considers both the resilience improvement during this phase and the time required for achieving this. Building on these four metrics, an additional metric can be defined, i.e., the area of the trapezoid, which thus all together gives a set of five resilience metrics. By considering piecewise linearity for the different phases of the trapezoid, the area of two right triangles (Phase I and III) and of a rectangular (Phase II) can be estimated.

When referring to power systems resilience, it is critical to distinguish the operational and infrastructure resilience. The operational resilience, as its name suggests, refers to the characteristics that would help a power system maintain operational strength and robustness in the face of a disaster, e.g. keep all the customers connected. The infrastructure resilience refers to the physical strength of a power system for minimizing the portion of the system that is damaged, collapsed or in general becomes nonfunctional.

In order to quantify the metrics of the operational and infrastructure resiliencies, different indicators should be used. In the case study application demonstrated later, where the focus is on quantifying the impact of windstorms on transmission networks, the following indicators are used:

- the amount of generation capacity (MW) and load demand (MW) that are connected and available for power generation and consumption respectively, during the event are used as indicators for the operational resilience; and

- the number of online transmission lines is used as an indicator for the infrastructure resilience.

By using a mixture of operational and infrastructure indicators, a relation between the operational and infrastructure resilience of the system and a complete picture of the prevailing system resilience level can be obtained. Further, capturing these resilience indicators at each simulation step (e.g. 30mins, 1hour, etc.) enables the multi-
Hardening measures: boosting the infrastructure resilience

- Undergrounding distribution and transmission lines

- Upgrading poles and structures with stronger, more robust materials

- Elevating substations

- Relocating facilities and network elements (e.g. substations and transmission lines) to areas less prone to external shocks

- Redundant transmission routes

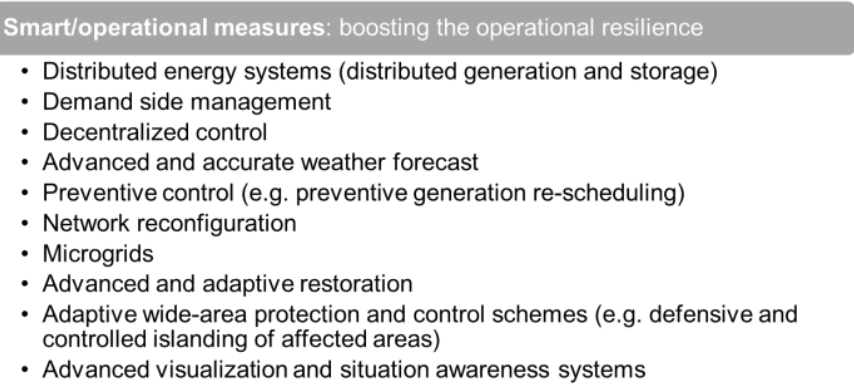

Fig. 3: Boosting power systems infrastructure and operational resilience

phase quantification of the resilience trapezoid curve of Fig. 1 and its evaluation using the proposed $\Phi \Lambda E \Pi$ metric system.

\section{Enhancing power systems resilience}

Based on the understanding of the concept of power systems resilience and the multi-phase resilience assessment discussed in the previous sections, several solutions can be applied for enhancing power systems resilience. These can be divided into two wide categories, namely hardening and smart/operational (Fig. 3). Hardening measures might be more resilience-effective than the operational ones, but are less cost-effective [8]. Further, operational measures take advantage of incoming information about the external shock through forecasting tools, applying thus actions that are adaptive to the prevailing conditions.

The hardening solutions mainly boost the infrastructure resilience, i.e., improve its robustness and resistance to the external shock. Their aim is thus to reduce the physical impact of the catastrophic events and prevent the incapacitation of large parts of the power grid. As seen in Fig. 3, there are numerous options available, such as using underground cables instead of overhead lines and upgrading the components with stronger, more robust infrastructures. It is worth mentioning that hardening measures which can be effective to a specific threat may have a negative effect in a different occasion. For example, undergrounding the lines would enhance the infrastructure resilience of a network against a typhoon, in case of an earthquake however, the repair duration of the damaged lines would result in a longer restoration phase.

The smart/operational solutions aim at enhancing the operational resilience of a power grid, i.e., providing the preventive and corrective operational flexibility for dealing effectively with the unfolding event. Decentralized energy systems with the large deployment of distributed energy resources (mainly distributed generation and storage), in conjunction with demand side management, can play a key role in the resilience boosting efforts. Generating, storing and controlling energy locally without the need of relying on long transmission lines that might be prone to different threats can make the network less vulnerable, as well as improve the response and restoration times. 
In addition, restoration techniques that are adaptive to widespread outages can enhance resilience as an additional operational solution [26-28]. After a natural disaster, the occurrence of multiple damages is very probable and thus repair crews play a critical role during restoration state. The efficient management [29] and allocation [30] of repair crews reduce restoration time, customer disconnections and increase power system resilience.

The contribution of microgrids to the resilience enhancement of areas prone to extreme weather has been demonstrated in several real cases, as for example in the United States of America, USA [31]. Microgrids, simply defined as low-voltage or medium-voltage grids that can be islanded and still supply, in a controlled coordinated way, all or part of their customers during emergencies [32]. Therefore, microgrids are proven to be one of the most effective ways of enhancing resilience to catastrophic events [33-37].

Further, smart preventive actions (e.g. preventive generation re-dispatch) based on advanced weather forecasting tools and adaptive wide-area protection and control schemes, e.g. defensive and controlled islanding [38, 39], can be an effective solution for the system operator. These schemes can be particularly critical in situations where the cascading phenomena are developing so quickly that is impossible for the human operator to react. Apparently, this is helpful provided that these schemes would operate reliably under any conditions, given their high complexity [40].

Lastly, but equally importantly, advanced visualization and situation awareness systems [41, 42] are critically important for monitoring the evolving system and weather conditions. The development of adequate situation awareness would enable the effective and timely decision-making by the system operator, in order to assess the damage, set priorities and proceed to the appropriate actions for mitigating the impacts by the event and restoring the system to its pre-event state.

\section{CASE Study ApPlication}

In order to demonstrate the concepts discussed in the previous sections, a case study application is presented next. In particular, the effect of windstorms on a 29-bus test version of the Great Britain (GB) transmission network is evaluated. Different resilience enhancement studies are also discussed, including both hardening and smart solutions. Due to the application of the proposed approach to transmission networks, important aspects related to distribution networks are not captured in this case study application, e.g. the complex process of distribution network restoration. However, it is worth-noting here that the proposed resilience assessment methodology and the $\Phi \Lambda E \Pi$ resilience metric system are capable of modelling and quantifying the response of distribution networks to extreme events, enabling the consideration of further critical aspects and smart grid technologies, e.g. microgrids, demand response and energy storage. This is provided the relevant information is available, and in particular the hazard characteristics and the fragility of the distribution components to this hazard.

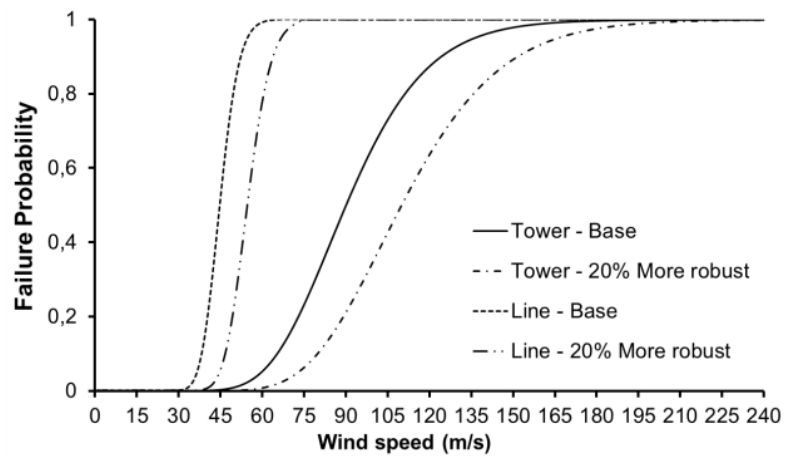

Fig. 4. Wind fragility curves of transmission lines and towers (for base and robust case studies)

\section{A. Time-series probabilistic resilience assessment tool}

A Sequential Monte Carlo-based probabilistic tool previously developed is used for evaluating the spatiotemporal impacts of extreme weather on the resilience of power systems, with application on the effect of windstorms on transmission networks $[38,43]$. In order to model the fragility of transmission networks to windstorms, the concept of fragility curves is used, which express the failure probability of the components as a function of the weather parameter. In this case study application, the elements considered are the transmission lines and towers, whose fragility curves are shown in Fig. 4 [17, 43, 44]. By mapping the wind profile of the windstorm hitting the transmission network to these fragility curves, the wind-dependent failure probabilities of the transmission lines and towers $(P(w))$ are obtained. These are then compared with a uniformly distributed random number $r \sim U(0,1)$. If $P(w)>r$, then the component is considered as tripped; otherwise it does not trip.

The wind-dependent operational status of the transmission elements is then inserted in the Sequential Monte Carlo engine to capture the multi-temporal and multi-spatial impact of the weather front as it moves across the transmission network. A simulation step of one hour and windstorm duration of $24 \mathrm{~h}$ is considered, which is assumed to hit the test network at the $50 \mathrm{~h}$ of the simulation. The wind speeds across the transmission network during the windstorm, which are the ones mapped at the fragility curves of Fig. 4, are obtained through MERRA reanalysis [43, 45]. However, as the wind data obtained by MERRA re-analysis represent hourly average wind speeds, it has been scaled-up in order to model severe windstorms in the simulations, with maximum wind speeds up to $50 \mathrm{~m} / \mathrm{s}$. At every simulation step, the operational and infrastructure resilience indicators are recorded for evaluating the performance of the network, as discussed in Section II-C.

A Mean Time To Repair $\left(M_{\left.T T R_{\text {normal }}\right)}\right.$ of $10 \mathrm{hrs}$ and $50 \mathrm{hrs}$ is assumed for the transmission lines and towers, respectively. In order to reflect the increasing damage and difficulty in accessing the affected areas for higher wind speeds, the following MTTRs are used [43]:

$$
M T T R= \begin{cases}M T T R_{\text {normal }}, & w_{\max } \leq 20 \mathrm{~m} / \mathrm{s} \\ k_{1} \times M T T R_{\text {normal }}, & 20 \mathrm{~m} / \mathrm{s}<w_{\max } \leq 40 \mathrm{~m} / \mathrm{s} \\ k_{2} \times M T T R_{\text {normal }}, & 40 \mathrm{~m} / \mathrm{s}<w_{\max } \leq 60 \mathrm{~m} / \mathrm{s}\end{cases}
$$




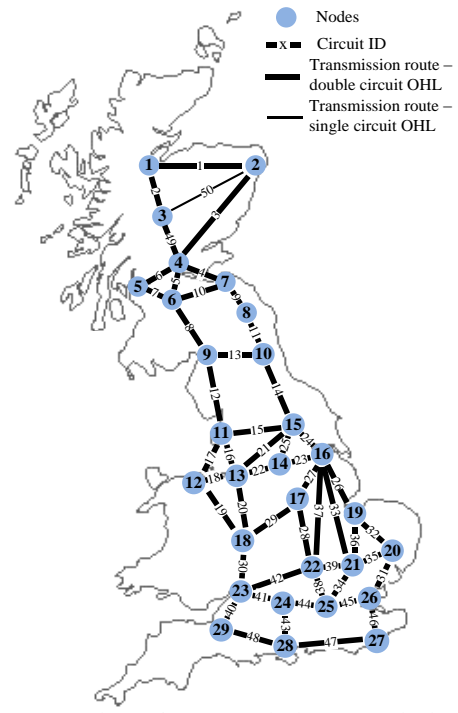

Fig. 5. The 29-bus test version of Great Britain transmission network

where $k_{1} \sim U(2,4)$ and $k_{2} \sim U(5,7)$ are numbers randomly generated within these predetermined ranges. It is assumed that no restoration takes place during the weather event due to safety reasons and difficulties in accessing the affected areas. Further, due to lack of data on the actual emergency and restoration procedures for the test network, it is considered that the time required for the disaster assessment, priority setting and emergency coordination in Phase II as well as the restoration times of the damaged components in Phase III are all included in the assumed MTTR shown in (1). However, the proposed simulation tool has the capability of including more detailed broken down information, if available. Ideally, these times would be provided by the system operator, which would help improve the accuracy of the simulation outputs.

\section{B. Test network}

The 29-bus test version of the GB transmission network shown in Fig. 5 is used as test network. This model consists of 29 nodes, 98 overhead transmission lines in double circuit configuration (which are assumed to be on the same tower) and one single circuit transmission line (i.e., between nodes 2 and 3) and 65 generators with an installed capacity of $75.3 \mathrm{GW}$, which are located at 24 nodes and include several generation technologies such as wind, nuclear, CCGT etc. Further details on this test network can be found in $[38,46]$.

\section{Quantifying the resilience trapezoid}

Fig. 6 shows the time-dependent resilience indicators for a grid-scale windstorm with a maximum wind speed of $50 \mathrm{~m} / \mathrm{s}$. It can be seen that the shape of these curves follows the resilience trapezoid of Fig. 1; that is, the three phases of the event (i.e., Phases I, II and III) can be clearly distinguished.

Therefore, by utilizing the approach described here, the resilience performance of a power grid during extreme weather can be effectively modelled, in terms of both operational and infrastructure resilience. Further, it can be observed that the restoration of the disconnected load follows the reconnection of the generation capacity, i.e., restoration of operational resilience, irrespectively of the recovery of the tripped lines, i.e., infrastructure resilience.

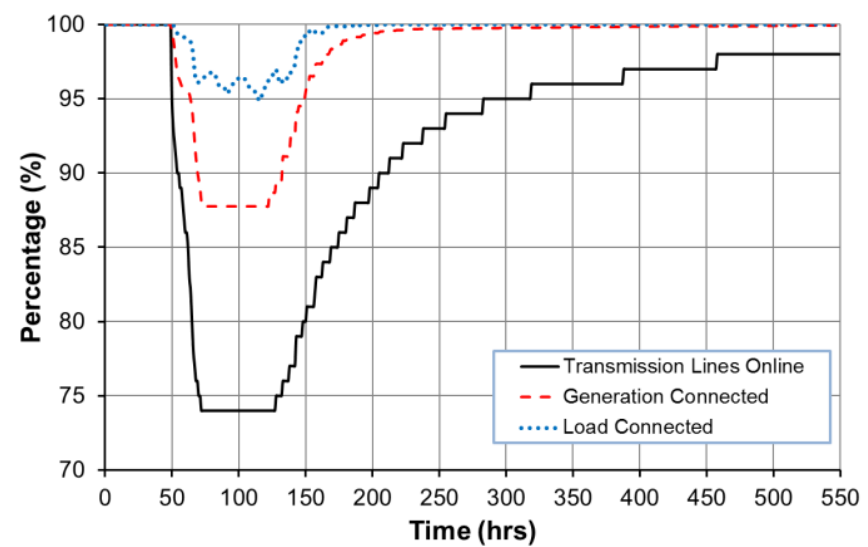

Fig. 6. Time-dependent resilience indicators for a windstorm with maximum wind speed of $50 \mathrm{~m} / \mathrm{s}$

TABLE IV

QUANTIFYING THE RESILIENCE TRAPEZOID USING THE $Ф$ $\Lambda$ $\Pi$ METRICS

\begin{tabular}{c|c|c|c}
\hline $\begin{array}{c}\text { Resilience } \\
\text { Metric }\end{array}$ & $\begin{array}{c}\text { Transmission } \\
\text { Lines }\end{array}$ & $\begin{array}{c}\text { Resilience Indicator } \\
\text { Generation } \\
\text { Connected }\end{array}$ & Load Connected \\
\hline \multirow{2}{*}{$\Phi$} & $\begin{array}{c}-1.083(\% \text { of Lines } \\
\text { tripped/hr) }\end{array}$ & $\begin{array}{c}-0.521(\% \text { of MW } \\
\text { lost } / \mathrm{hr})\end{array}$ & $\begin{array}{c}-0.249(\% \text { of } \\
\text { MW lost } / \mathrm{hr})\end{array}$ \\
\hline \multirow{2}{*}{$\Lambda$} & $\begin{array}{c}26(\% \text { of Lines } \\
\text { tripped) }\end{array}$ & $\begin{array}{c}12.5(\% \text { of MW } \\
\text { lost })\end{array}$ & $\begin{array}{c}5.99(\% \text { of MW } \\
\text { lost })\end{array}$ \\
\hline$E$ & $53(\mathrm{hrs})$ & $54(\mathrm{hrs})$ & $57(\mathrm{hrs})$ \\
\hline$\Pi$ & $\begin{array}{c}0.058(\% \text { of Lines } \\
\text { restored/hr) }\end{array}$ & $\begin{array}{c}0.033(\mathrm{MW} \\
\text { restored } / \mathrm{hr})\end{array}$ & $\begin{array}{c}0.072(\mathrm{MW} \\
\text { restored } / \mathrm{hr})\end{array}$ \\
\hline
\end{tabular}

Table IV shows the $\Phi \Lambda E \Pi$ resilience metrics, which provides a complete resilience assessment framework, enabling the effective quantification of the operational and infrastructure resilience of a power system during the different phases that it may reside during an event. It has to be noted here that the $\Phi$-metric is negative as the resilience level is decreasing during the event, i.e., Phase I of the resilience trapezoid of Fig. 1. It can also be seen that the $E$-metric of the generation and demand connected (54 and 57hrs respectively) is higher than the one of transmission lines (53hrs); this is mainly due to the operational and network constraints that do not allow the immediate recovery of the available power to be either generated or consumed.

\section{Quantifying the effect of hardening and smart resilience enhancement strategies}

The effect of two resilience enhancement strategies is next quantified using the proposed resilience metric framework.

In particular, the first strategy deals with evaluating the influence of making the network more robust, which is achieved by increasing the robustness of the transmission lines and towers as shown in Fig. 4. This solution thus contributes to the hardening of the transmission network, reducing the resilience degradation during Phase $I$ of the resilience trapezoid in Fig. 1.

The implementation of smart strategies can improve the responsiveness of the network which could lead to lower restoration and recovery times (i.e., lower duration of Phases $I I$ and III of the resilience trapezoid respectively), by either providing preventive and corrective operational flexibility and resources or improving the situational awareness of the 
network operators (see Fig. 3). In order to model the decrease in the restoration times as a direct effect of implementing smart strategies, the MTTR used in the simulations is reduced by $20 \%$. This makes the network more responsive to the hazard, which is referred to here as response case scenario. This particular decrease in MTTR is used here following discussions with National Grid, the GB transmission system operator, on the estimated impact that smart grid technologies might have on the responsiveness of the network. However, it has to be clarified that this can be system- and hazard-specific, depending as well on the smart grid technology and other operational measures to be applied.

Fig. 7 shows the transmission lines online (\%) for the following scenarios, namely base case without enhancement measures, $20 \%$ more robust and $20 \%$ more responsive. Table $\mathrm{V}$ presents the $\Phi \Lambda E \Pi$ resilience metrics and Fig. 8 shows the area metric, both corresponding to Fig. 7. A linear approximation of the transitions between the states of the resilience trapezoid of Fig. 1 has been made here for calculating the $\Phi \Lambda E \Pi$ resilience metrics of Table $\mathrm{V}$ for demonstration and quantification purposes. The area metric in Fig. 8 is shown for the different phases (i.e., Phase I, II and III) of the resilience trapezoid. By using a combination of the $\Phi \Lambda E \Pi$ resilience metrics and the area metric, useful insights on the contribution of the possible resilience enhancement strategies during each phase of the resilience trapezoid can be obtained. It can be seen from Fig. 7 that making the transmission network more robust, as expected, reduces significantly the transmission lines going offline during the weather event. Also, it can be observed that making the network smarter by improving the response and restoration of the tripped components faster results in a lower duration of the post-disturbance degraded state (Phase II, see Fig. 1) and reduces the restoration time of the infrastructure (Phase III, see Fig. 1). Similar patterns are observed from the other resilience indicators, i.e., load and generation capacity connected. Therefore, important conclusions on the aspects affecting the shape of the resilience trapezoid can be drawn from these simple case studies. It has to be noted that different smart operational strategies could have different impact on the resilience trapezoid, for example affecting the slope of the resilience degradation in Phase I rather than affecting Phases $I I$ and $I I I$.

The $\Phi \Lambda E \Pi$ resilience metrics corresponding to Fig. 7 in Table $\mathrm{V}$ show that these metrics are significantly affected by making the network more robust and responsive, respectively. In particular, increasing the robustness has an impact on $\Phi, \Lambda$ and $\Pi$ metrics. Improving the responsiveness to the event influences mainly the $E$ and $\Pi$ metrics; that is, the duration of the post-event degraded state is the lowest and the recovery slope following the event the highest. These illustrative case studies thus clearly demonstrate the effect of different aspects on the resilience performance of a power system.

Further, it can be seen in Fig. 8 that due to the lowest resilience degradation in the robust case scenario, the resulting areas of the trapezoid phases are the smallest for this scenario. It can also be observed that the largest area is the one of Phase

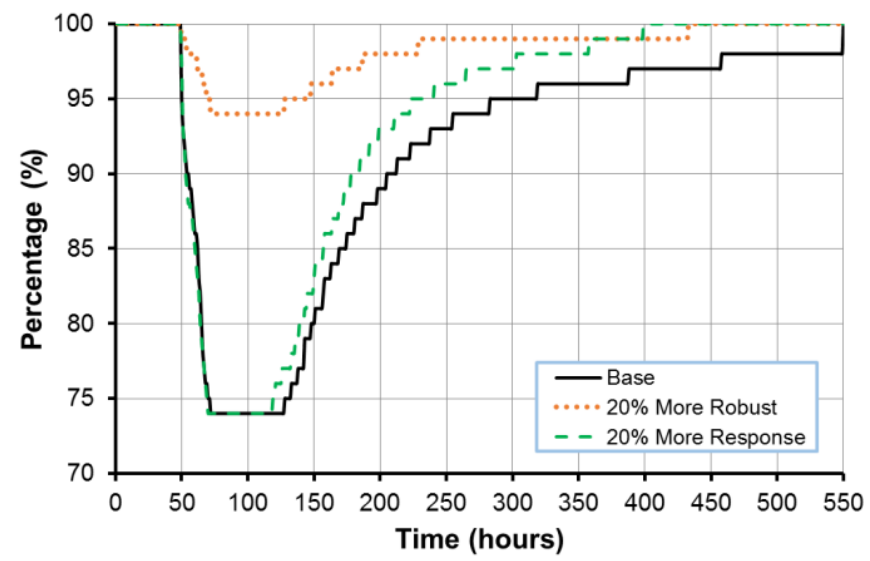

Fig. 7. Transmission lines online (\%) for a windstorm with maximum wind speed of $50 \mathrm{~m} / \mathrm{s}$ for different case studies

TABLE V

THE $\Phi$

\begin{tabular}{c|c|c|c}
\hline $\begin{array}{c}\text { Resilience } \\
\text { Metric }\end{array}$ & Base & \multicolumn{3}{c}{$\begin{array}{c}\text { Resilience Indicator } \\
20 \% \text { More Robust }\end{array}$} & $\begin{array}{c}20 \% \text { More } \\
\text { Response }\end{array}$ \\
\hline$\Phi$ & $\begin{array}{c}-1.083(\% \text { of } \\
\text { Lines tripped/hr) }\end{array}$ & $\begin{array}{c}-0.25(\% \text { of Lines } \\
\text { tripped/hr) }\end{array}$ & $\begin{array}{c}-1.083(\% \text { of } \\
\text { Lines tripped } / \mathrm{hr})\end{array}$ \\
\hline$\Lambda$ & $\begin{array}{c}26(\% \text { of Lines } \\
\text { tripped) }\end{array}$ & $\begin{array}{c}6(\% \text { of Lines } \\
\text { tripped })\end{array}$ & $\begin{array}{c}26(\% \text { of Lines } \\
\text { tripped })\end{array}$ \\
\hline$E$ & $53(\mathrm{hrs})$ & $53(\mathrm{hrs})$ & $44(\mathrm{hrs})$ \\
\hline$\Pi$ & $\begin{array}{c}0.058(\% \text { of Lines } \\
\text { restored/hr) }\end{array}$ & $\begin{array}{c}0.019(\% \text { of Lines } \\
\text { restored } / \mathrm{hr})\end{array}$ & $\begin{array}{c}0.092(\% \text { of Lines } \\
\text { restored } / \mathrm{hr})\end{array}$ \\
\hline \multicolumn{3}{|c}{}
\end{tabular}

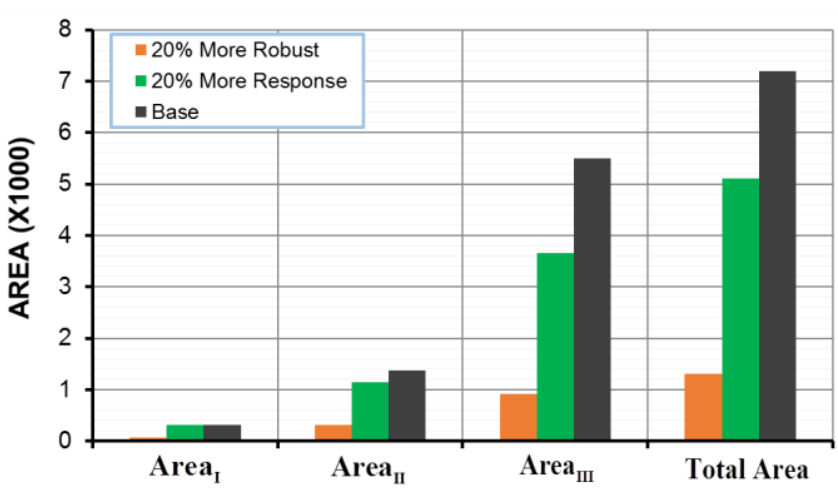

Fig. 8. The area metric using the resilience indicator of transmission lines online for different case scenarios

$I I I$, as this is the restoration phase that has a significantly larger duration than the other phases of the trapezoid.

\section{E. Systematic approach for resilience enhancement}

Resilience enhancement approaches might be more resilience effective than others, however they might be less cost effective. Hence, in order to apply targeted resilience enhancement to the areas and components that contribute more to the resilience boosting, while reducing the investment costs, a risk-based approach is applied next. In particular, the Resilience Achievement Worth $(R A W)$ index of each transmission corridor is estimated as follows:

$$
R A W=\frac{R\left(R_{n}=1\right)-R}{R} \times 100
$$




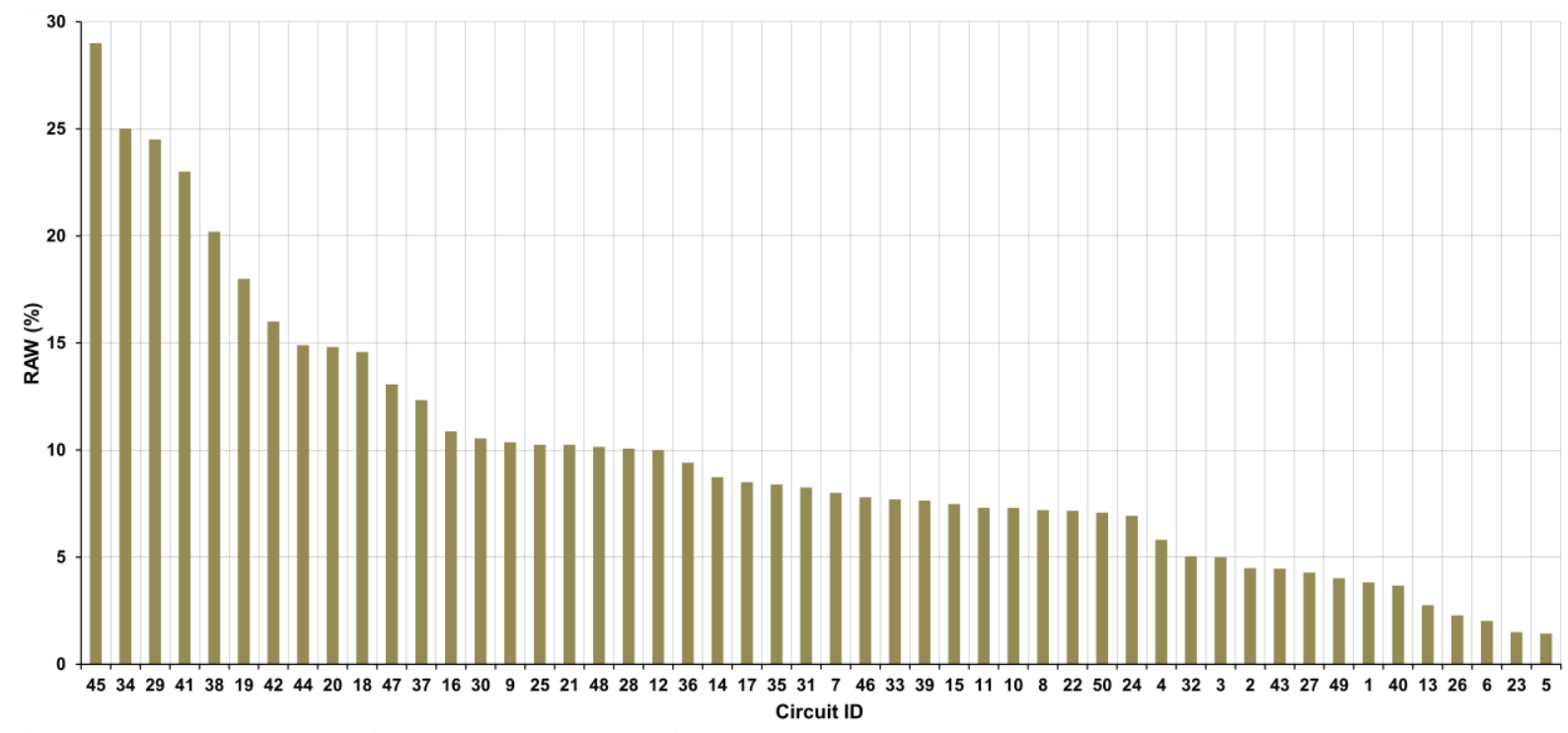

Fig. 9. Resilience achievement worth (\%) for maximum wind speed of $50 \mathrm{~m} / \mathrm{s}$ (the Circuit IDs are shown in Fig. 5)

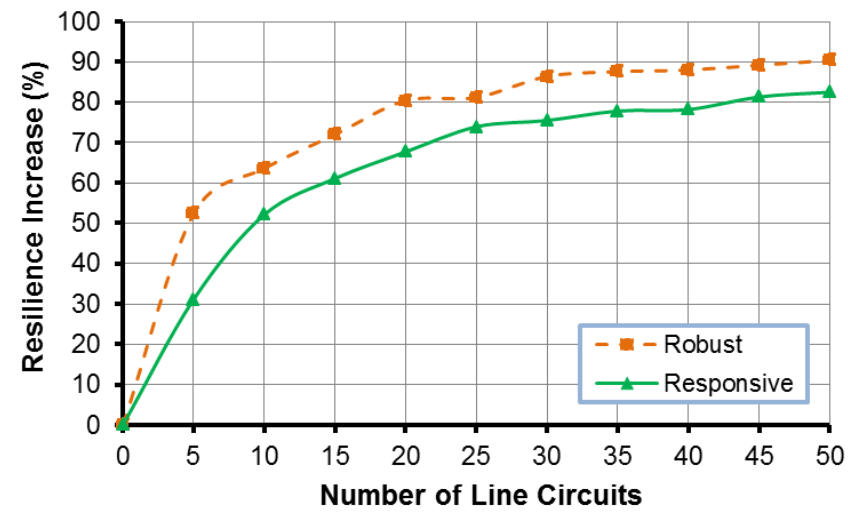

Fig. 10. Resilience increase when applying the robust and response scenarios based on the $R A W$ index

where $R$ is the actual overall system resilience (e.g. demand connected during the event) and $R\left(R_{n}=1\right)$ is the overall system resilience when the transmission corridor $n$ is made $100 \%$ resilient during the event, i.e. $R_{n}=1 . R A W$ thus shows the increase in the overall system resilience when each corridor is subsequently made $100 \%$ robust, i.e. assuming it will never trip during the extreme event. Any resilience indicator aforementioned can be used in (2).

Fig. 9 shows the $R A W(\%)$ of the transmission corridors using as resilience indicator the load connected for maximum wind speed of $50 \mathrm{~m} / \mathrm{s}$. Therefore, the $R A W$ in Fig. 9 shows the percentage increase in the load connected when it is considered that each of the transmission corridors has a zero probability of failing during the windstorm. These results provide useful insights on the contribution of each transmission corridor to the system resilience, and in turn on the most appropriate roadmap for the resilience enhancement efforts, in order to satisfy both the resilience and investment goals. The $R A W$ analysis can thus be used for prioritizing, in a risk-based way, the critical lines to be enhanced for achieving higher resilience levels to future events. It has to be noted here that the $R A W$ of each corridor might vary for windstorms with different intensity.

Fig. 10 shows an example of applying the resilience enhancement strategies considered in the previous section, i.e., making the transmission lines 20\% more robust and responsive respectively, based on the $R A W$ index of each transmission corridor. These strategies are subsequently applied to groups of five lines depending on their criticality, i.e., first applied to the first five more critical lines (with IDs $45,34,29,41$ and 38), then to the first ten more critical lines (with IDs 45, 34, 29, 41, 38, 19, 42, 44, 20 and 18) and so on until all fifty circuits of the test network become more robust and responsive respectively. It can be clearly seen that making the lines more robust has a higher effect than improving the responsiveness, i.e., reducing their restoration time. Further, this resilience increase is sharper when the first more critical lines are reinforced and becomes smoother when the less critical lines (i.e., lower $R A W$ index) are enhanced. It has to be noted here that the contribution of any hardening or smart resilience enhancement strategy can be evaluated following the same approach.

\section{F. A smart, risk-based operational measure (defensive islanding)}

As mentioned in Section II-D, smart/operational solutions applied for extreme weather events could enhance the resilience of the network in a cost effective way. Defensive islanding is a preventive operational measure which can be applied during events, where cascading outages are very probably triggered [47], causing large area blackouts [48]. By splitting the system into stable and self-sufficient islands, the spread of the failure from the affected area to the rest of the network is avoided. Defensive islanding could thus be effective in case of region-scale extreme events, by isolating the affected area and preventing a disturbance propagation.

Due to the stochastic impact of such events and the continuously changing structure of the network as a result of multiple failures, it is not clear whether the defensive 
islanding would support the network resilience, or further worsen it. To address this issue, a smart, adaptive Severity Risk Index (SRI) is proposed, which considers the network structure, the loading conditions and the impact and probability of the events that might occur during a disturbance. Based on SRI, which captures the prevailing system conditions during an extreme event, the operators' decision-making on whether to apply defensive islanding is supported. This $S R I$ is defined as:

$$
S R I=\sum_{k=1}^{K} P_{k} \times m_{k}
$$

where, $P_{k}$ and $I m_{k}$ is the probability and the impact of scenario $k$, respectively. The impact of each scenario is considered equal to the amount of load shedding (in $\mathrm{MWh}$ ) that is carried out for leading the system in a stable state. $K$ is the set of selected failure scenarios. The set of selected scenarios represents all possible failures selected to be investigated. Comparing SRI values with a pre-specified threshold (network parameter), the operator is notified for activating the islanding [38].

The set of selected failure scenarios could be created using weather-dependent failure probabilities, as obtained by the fragility curves. At each simulation step the lines having failure probabilities higher than a threshold are considered as vulnerable lines and are used to generate all possible failure scenarios. In case of $N$ vulnerable lines, the number of possible failure scenarios is $2^{N}$. The scenarios that have probability higher than a pre-specified threshold are used to compute SRI. The thresholds are determined by the operator and their values depends on a trade-off between computational complexity and security level.

To deal with the computation complexity scenario reduction techniques are used (to reduce the number of scenarios in a manageable size). In case the investigation of all the selected failure scenarios is not computationally tractable, scenario reduction techniques use the set of selected scenarios to produce a number of representative scenarios which are considered in the estimations of SRI [49].

Considering the cascading events that are caused only by thermal overloads, the impact of each scenario can be obtained as illustrated in [38]. Defensive islanding enhances the resilience of the system during extreme events (Phase I) by mitigating their impact on power system. Considering that the overloaded lines which are tripped by the protection are reconnected the next hour, at the end of Phase I, the number of faulted lines due to windstorm will be the same with or without defensive islanding. Therefore, defensive islanding would be effective only during the extreme event and not in the post-event phase.

The effectiveness of the defensive islanding is assessed by considering a windstorm that hits the North and Central-East region of the GB network. Fig. 11 shows the transmission lines and load online (\%) with and without defensive islanding only for Phase I. For this test case the maximum wind speed is $50 \mathrm{~m} / \mathrm{s}$ and the hourly load demand is increased by $20 \%$ in order to stress the system and enable the effective demonstration of the benefits gained by defensive islanding. It is observed that defensive islanding improves the operational

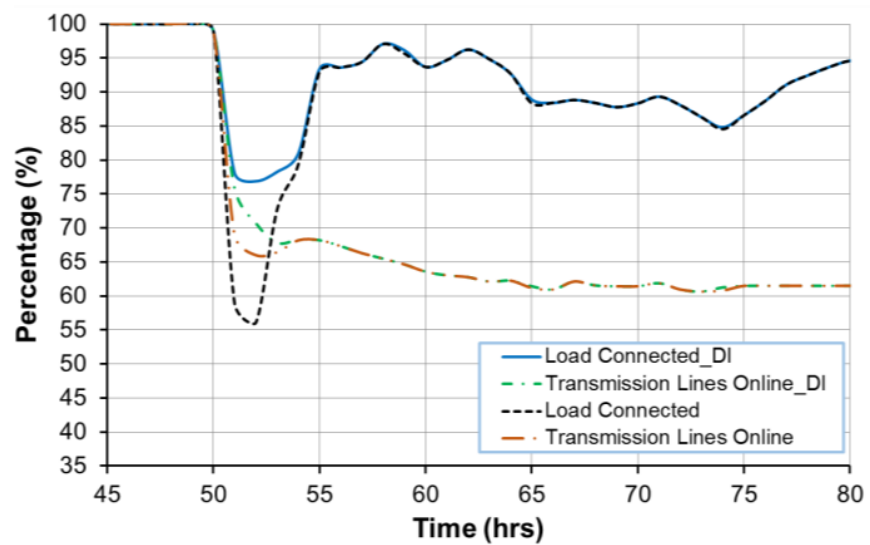

Fig. 11. Transmission lines and load online with and without the application of defensive islanding for a grid-scale windstorm

and infrastructure resilience in the first hours that the windstorm hits the system. Due to the loss of a large number of lines in the first few hours, cascading events occurred that lead to load disconnection in the South area of GB where large urban centers are found. For this reason, it is observed that load served in the first few hours is lower, compared with the following hours when the faulted lines are less. The following hours, several lines have already tripped and the number of failed lines at each hour is reduced considerably. As a result, cascading events do not occur and thus load online curve does not have a sharp decline like in the first hours. Thus, resilience does not benefit from applying defensive islanding.

\section{CONCLUSIONS}

Resilience is an emerging concept in the area of power systems. As such, there is still confusion and even misperception of what it really denotes and how it can be modelled and quantified in a systematic and effective way.

In this paper the concept of power systems resilience expressed as the multi-phase resilience performance of a power system subject to catastrophic events is put into a conceptual framework based on a resilience trapezoid. A discussion on the key resilience features and the main hardening and smart resilience enhancement solutions is also provided. Further, a quantitative resilience framework is proposed, based on a set of resilience metrics capable of effectively capturing the behavior of a power system during an extreme weather event and the contribution of hardening and smart operational strategies to the resilience of a power system.

In order to demonstrate the applicability of the different concepts discussed in the paper, a case study application using the 29-bus test version of the GB transmission network is developed. In this application, the resilience trapezoid is modelled using both operational and infrastructure resilience indicators. It is further quantified using the $\Phi \Lambda E \Pi$ and area resilience metrics, while investigating the effects of different hardening and smart resilience enhancement solutions. This clearly highlights the capability of the proposed assessment framework to quantify power systems resilience and also define the contribution of relevant strategies in making power systems stronger, smarter and better prepared to future events. 
Future work includes the co-simulation of transmission and distribution networks that would help get a better understanding of a wider range of aspects that can affect the resilience performance of a power system as a whole, e.g. the duration of load reconnection following such extreme events.

\section{REFERENCES}

[1] S. M. Rinaldi, J. P. Peerenboom, and T. K. Kelly, "Identifying, understanding, and analyzing critical infrastructure interdependencies," IEEE Control Systems, , vol. 21, no. 6, pp. 11-25, 2001.

[2] G. Andersson, P. Donalek, R. Farmer, N. Hatziargyriou, I. Kamwa, P. Kundur, et al., "Causes of the 2003 major grid blackouts in North America and Europe, and recommended means to improve system dynamic performance," IEEE Trans. Power Syst. vol. 20, no. 4, pp. 1922-1928, 2005.

[3] P. Hines, J. Apt, and S. Talukdar, "Large Blackouts in North America: Historical Trends and Policy Implications," Energy Policy, vol. 37, pp. 5249-5259, 2009

[4] Y. Wang, C. Chen, J. Wang, and R. Baldick, "Research on Resilience of Power Systems Under Natural Disasters - A Review," IEEE Trans. Power Syst., vol. 31, no. 2, pp. 1604-1613, 2016.

[5] C. S. Holling, "Resilience and Stability of Ecological Systems," Annual Review of Ecology and Systematics, vol. 4, pp. 1-23, 1973.

[6] National Infrastructure Advisory Council (NIAC), "A Framework for Establishing Critical Infrastructure Resilience Goals," USA, 2010.

[7] Cabinet Office, "Keeping the Country Running: Natural Hazards and Infrastructure," UK, 2011.

[8] M. Panteli and P. Mancarella, "The Grid: Stronger, Bigger, Smarter?: Presenting a Conceptual Framework of Power System Resilience," IEEE Power and Energy Magazine, vol. 13, no. 3, 2015.

[9] M. Panteli and P. Mancarella, "Influence of Extreme Weather and Climate Change on the Resilience of Power Systems: Impacts and Possible Mitigation Strategies," Electric Power Systems Research, vol. 127 , pp. 259-270, 2015

[10] K. Tierney and M. Bruneau, "Conceptualizing and Measuring Resilience: A Key to Disaster Loss Reduction," TR News, May-June 2007.

[11] UK Energy Research Center (UKERC), "Energy 2050 project," 2009.

[12] M. Chaudry, P. Ekins, K. Ramachandran, A. Shakoor, J. Skea, G. Strbac, et al., "Building a Resilient UK Energy System," 2011.

[13] G. P. Cimellaro, A. M. Reinhorn, and M. Bruneau, "Framework for analytical quantification of disaster resilience," Engineering Structures, vol. 32, no. 11, pp. 3639-3649, 2010

[14] M. Ouyang, L. Dueñas-Osorio, and X. Min, "A three-stage resilience analysis framework for urban infrastructure systems," Structural Safety, vol. 36-37, pp. 23-31, 2012.

[15] M. Ouyang and L. Dueñas-Osorio, "Multi-dimensional hurricane resilience assessment of electric power systems," Structural Safety, vol. 48, pp. 15-24, 2014.

[16] S. Espinoza, M. Panteli, P. Mancarella, and H. Rudnick, "Multi-phase assessment and adaptation of power systems resilience to natural hazards," Electric Power Systems Research, vol. 136, pp. 352-361, 2016.

[17] M. Panteli and P. Mancarella, "Modelling and Evaluating the Resilience of Critical Electrical Power Infrastructure to Extreme Weather Events," IEEE Systems Journal, Early access, 2015.

[18] M. R. Bhuiyan and R. N. Allan, "Inclusion of weather effects in composite system reliability evaluation using sequential simulation," IEE Proc. Gen., Trans. and Distr., vol. 141, no. 6, pp. 575-584, 1994.

[19] Y. Liu and C. Singh, "Evaluation of hurricane impact on composite power system reliability considering common-cause failures," Int. J. of Syst. Ass. Eng. and Management, vol. 1, no. 2, pp. 135-145, 2010.

[20] R. Francis and B. Bekera, "A metric and frameworks for resilience analysis of engineered and infrastructure systems," Reliability Engineering \& System Safety, vol. 121, pp. 90-103, 2014.

[21] D. Henry and J. Emmanuel Ramirez-Marquez, "Generic metrics and quantitative approaches for system resilience as a function of time," Rel. Eng. \& Syst. Safety, vol. 99, pp. 114-122, 2012.

[22] A. Kwasinski, "Quantitative Model and Metrics of Electrical Grids'Resilience Evaluated at a Power Distribution Level," Energies, vol. 9, no. 2, 2016.
[23] M. Ouyang and L. Dueñas-Osorio, "Time-dependent resilience assessment and improvement of urban infrastructure systems," Chaos, vol. 22, p. 033122, 2012.

[24] D. A. Reed, K. C. Kapur, and R. D. Christie, "Methodology for Assessing the Resilience of Networked Infrastructure" IEEE Systems Journal, vol. 3, no, 2, pp. 174-180, May 2009.

[25] M. Panteli, P. Mancarella, D. Trakas, E. Kyriakides, and N. Hatziargyriou, "Metrics and Quantification of Operational and Infrastructure Resilience in Power Systems," IEEE Trans. Power Syst., Early Access, Feb. 2017.

[26] M. Choobineh and S. Mohagheghi, "Emergency electric service restoration in the aftermath of a natural disaster," in 2015 IEEE Global Humanitarian Technology Conference (GHTC), pp. 183-190.

[27] A. Gholami and F. Aminifar, "A Hierarchical Response-Based Approach to the Load Restoration Problem," IEEE Trans. Smart Grid, Early access, pp. 1-10, 2015.

[28] Y. Hou, C. C. Liu, K. Sun, P. Zhang, S. Liu, and D. Mizumura, "Computation of Milestones for Decision Support During System Restoration," IEEE Trans. Power Syst, vol. 26, no. 3, pp. 1399-1409, 2011

[29] A. Arab, A. Khodaei, S. K. Khator, K. Ding, V. A. Emesih, and Z. Han, "Stochastic Pre-hurricane Restoration Planning for Electric Power Systems Infrastructure," IEEE Trans. Smart Grid, vol. 6, no. 2, pp. 1046-1054, 2015.

[30] C. Lirong, W. Kuo, H. T. Loh, and M. Xie, "Optimal allocation of minimal \& perfect repairs under resource constraints," IEEE Trans. Reliability, vol. 53, no. 2, pp. 193-199, 2004.

[31] Executive Office of the President, "Economic Benefits of Increasing Electric Grid Resilience to Weather Outages," USA, August 2013.

[32] N. Hatziargyriou, Microgrids: Architectures and Control, Wiley\&Sons, 2014.

[33] A. Khodaei, "Resiliency-Oriented Microgrid Optimal Scheduling," IEEE Trans. Smart Grid, vol. 5, no. 4, pp. 1584-1591, 2014.

[34] Z. Wang and J. Wang, "Self-Healing Resilient Distribution Systems Based on Sectionalization Into Microgrids," IEEE Trans. Power Systems, vol. 30, no. 6, pp. 3139-3149, 2015.

[35] C. Chen, J. Wang, F. Qiu, and D. Zhao, "Resilient Distribution System by Microgrids Formation After Natural Disasters," IEEE Trans. Smart Grid, vol. 7, no. 2, pp. 958-966, 2016.

[36] C. L. Moreira, F. O. Resende, and J. A. P. Lopes, "Using Low Voltage MicroGrids for Service Restoration," IEEE Trans. Power Systems, vol. 22, no. 1, pp. 395-403, 2007.

[37] G. Strbac, N. Hatziargyriou, J. P. Lopes, C. Moreira, A. Dimeas, and D. Papadaskalopoulos, "Microgrids: Enhancing the Resilience of the European Megagrid," IEEE Power and Energy Magazine, vol. 13, no. 3, pp. 35-43, May-June 2015.

[38] M. Panteli, D. N. Trakas, P. Mancarella, and N. D. Hatziargyriou, "Boosting the Power Grid Resilience to Extreme Weather Events Using Defensive Islanding," IEEE Trans. Smart Grid, vol. 7, no. 6, pp. 1-10, Nov. 2016.

[39] D. N. Trakas, E. M. Voumvoulakis, and N. D. Hatziargyriou, "Controlled islanding of power networks using machine learning algorithm," in MedPower 2014, pp. 1-6, 2014.

[40] M. Panteli, P. A. Crossley, and J. Fitch, "Quantifying the reliability level of system integrity protection schemes," IET Gen., Trans. and Distr., vol. 8, no. 4, pp. 753-764, April 2014.

[41] M. Panteli and D. S. Kirschen, "Situation awareness in power systems: Theory, challenges and applications," Electric Power Systems Research, vol. 122, pp. 140-151, 2015.

[42] M. Panteli, P. A. Crossley, D. S. Kirschen, and D. J. Sobajic, "Assessing the Impact of Insufficient Situation Awareness on Power System Operation,", IEEE Trans. Power Syst., vol. 28, no. 3, pp. 29672977, 2013.

[43] M. Panteli, C. Pickering, S. Wilkinson, R. Dawson, and P. Mancarella, "Power System Resilience to Extreme Weather: Fragility Modelling, Probabilistic Impact Assessment, and Adaptation Measures," IEEE Trans. Power Syst., Early Access, Dec. 2016.

[44] M. Kirsty and K. R. W. Bell, "Wind Related Faults on the GB Transmission Network," in Probabilistic Methods Applied to Power Systems (PMAPS), Durham, UK, 2014, pp. 1-6.

[45] MERRA Re-analysis. Available: http://gmao.gsfc.nasa.gov/, Last Accessed: September 2016

[46] M. Belivanis and K. Bell, "Representative GB Network Model," 2011, Available: www.maths.ed.ac.uk/optenergy/NetworkData/reducedGB/, Last Accessed: September 2016 
[47] D. Xianzhong and S. Sheng, "Self-Organized Criticality in Time Series of Power Systems Fault, Its Mechanism, and Potential Application," IEEE Trans. Power Systems, vol. 25, no. 4, pp. 1857-1864, 2010.

[48] D. P. Nedic, I. Dobson, D. S. Kirschen, B. A. Carreras, and V. E. Lynch, "Criticality in a cascading failure blackout model," Electrical Power and Energy Systems, vol. 28, pp. 627-633, 2006.

[49] D. N. Trakas, M. Panteli, P. Mancarella, and N. D. Hatziargyriou, "A Severity Risk Index for High Impact Low Probability Events in Transmission Systems due to Extreme Weather," in 2016 IEEE PES Innovative Smart Grid Technologies (ISGT Europe), Ljubljana, Slovenia, 2016, pp. 1-6.

\section{BIOGRAPHIES}

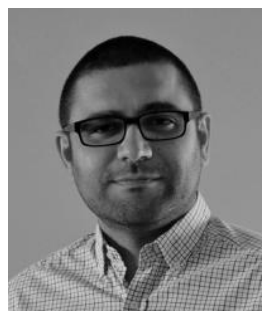

Mathaios Panteli (S'09, M'13) received the MEng degree in 2009 from Aristotle University of Thessaloniki, Greece, and the $\mathrm{PhD}$ degree in Electrical Power Engineering from The University of Manchester (UoM), UK in 2013, where he also worked as a Post-doctoral Research Associate for a few years. In September 2015, he joined University of Cyprus as a Research Associate and University of Nicosia, Cyprus, as an Adjunct Lecturer. He is currently a Lecturer in the Power and Energy Division at UoM. His main research interests include analysis and prevention of blackouts, risk and resilience assessment of power systems and integrated modelling of critical infrastructures.

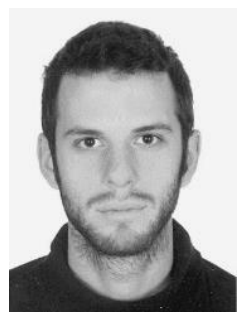

Dimitris N. Trakas (S'16) received his diploma in Electrical and Computers Engineering from National Technical University of Athens (NTUA), Greece in 2009, and the Master of Sciences in Energy Production and Management from NTUA in 2011. He is currently a Ph.D. student at Electric Power Division of NTUA. His research interests include decentralized control of power systems, resilience assessment and enhancement of power systems.

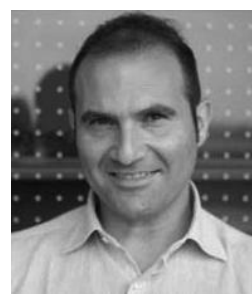

Pierluigi Mancarella (M'08-SM'14) received the $\mathrm{MSc}$ and $\mathrm{PhD}$ degrees in electrical energy systems from the Politecnico di Torino, Torino, Italy, in 2002 and 2006, respectively. He is currently Chair Professor of Electrical Power Systems at The University of Melbourne, Australia, and Professor of Smart Energy Systems at The University of Manchester, UK. His research interests include multi-energy systems, power system integration of low carbon technologies, network planning under uncertainty, and risk and resilience of smart grids. Pierluigi is an Editor of the IEEE Transactions on Smart Grid, an Associate Editor of the IEEE Systems Journal, and an IEEE PES Distinguished Lecturer.

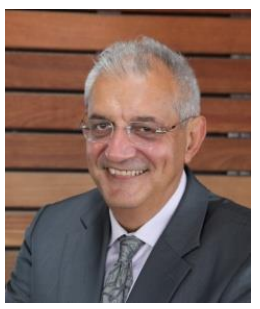

Nikos D. Hatziargyriou is Chairman and CEO of the Hellenic Distribution Network Operator. Since 1984 he is with the Power Division of the Electrical and Computer Engineering Department of the National Technical University of Athens and since 1995 he is full professor in Power Systems. From February 2007 to September 2012, he was Deputy CEO of the Public Power Corporation (PPC) of Greece, responsible for Transmission and Distribution Networks, island DNO and the Center of Testing, Research and Prototyping. $\mathrm{He}$ is Fellow Member of IEEE, past Chair of the Power System Dynamic Performance Committee, Honorary member of CIGRE and past Chair of CIGRE SC C6 "Distribution Systems and Distributed Generation". He is cochair of the EU Technology and Innovation Platform on Smart Networks for Energy Transition. He is member of the Energy Committee of the Athens Academy of Science. He has participated in more than $60 \mathrm{R} \& \mathrm{D}$ Projects funded by the EC and the industry, and has coordinated among others, the EU
"CARE", "MORE CARE", "MERGE", "Microgrids" and "More Microgrids" projects. He is Editor in Chief of the IEEE Transactions on Power Systems and member of the Editorial Board of IEEE Transactions on Sustainable Development and the IEEE Power and Energy magazine. He is author of the book "Microgrids: Architectures and Control" and of more than 200 journal publications and 500 conference proceedings papers. He is included in the 2016 Thomson Reuters' list of the top 1\% most cited researchers. 